\title{
Decline of the Rave Inspired Clubculture in China: State Suppression, Clubber Adaptations and Socio-Cultural Transformations
}

\author{
MATTHEW M. CHEW \\ HONG KONG BAPTIST UNIVERSITY (HONG KONG SAR)
}

\begin{abstract}
This study examines the development of rave inspired clubculture in China between the late $1990 \mathrm{~s}$ and the present. It focuses in particular on the harsh suppression of clubland by the Chinese state in 2000, the reactions of clubbers and the club industry, and the clubcultural transformations that resulted from the suppression. A nationally coordinated anti-drug campaign that specifically targeted dance clubs was orchestrated by the central government and it has forced many clubs to close down. The rent-seeking practices of local officials also greatly intimidated clubbers. Clubbers and club operators adapted to the adverse circumstances by transforming club spaces and inventing new club practices. Although these adaptations have kept clubculture alive, they also generated negative sociocultural impacts: the undermining of sociality inside dance clubs, the weakening of the communal dimension of clubculture and the exacerbation of socio-economic stratification in clubland.
\end{abstract}

\section{Keywords}

clubculture, night-time economy, sociality, dance clubs, rave party, Ecstasy, Chinese nightlife

Important elements of rave culture including the rave party format, Ecstasy use and electronic dance music emerged in the UK in the late 1980s (McKay 1998; Reynolds 1998; Thornton 1996). This new clubculture faced a number of problems in the 1990 s - clubs were increasingly commercialized and controlled by corporations, electronic dance music has been increasingly mainstreamed, and clubbing was increasingly considered a tourist income generator for city planners and local officials (Chatterton and Hollands 2003). At the same time, rave culture successfully diffused outside developed Western economies and inspired different versions of clubcultures in localities throughout the globe (eg. Chew forthcoming 2009a; Sliavaite 1998; Swedenburg 2001; Saldanha 2002). The rave scene has entered a period of slower growth in the West since the early 2000s (McCall 2001; Owen 2003). But what has happened to rave inspired clubcultures in non-Western societies? Has it faced a similar set of problems and did it peak at the same time as it did in the West? This study examines the case of China and finds that although the rave inspired clubculture there also went into decline in the early 2000s, the circumstances under which it did was markedly 
different from those in the West. Developed along a different trajectory and under a different social context, clubculture in China was not plagued by problems experienced in the West. Instead, the most formidable problem that it faced was forceful suppression by the state. This problem is not unexpected given the Chinese state's authoritarianism, paternalistic treatment of its citizens and fear of social disorder.

The study's substantive analysis is organized in three parts. Firstly, I will document how the Chinese government suppressed the rave inspired clubculture through the local police's harsh and self-serving persecution of clubbers. Second, I will illustrate how clubbers and club operators adapted to the repressive environment by inventing new clubbing practices and club spaces to protect themselves. Thirdly, I will analyze the social and clubcultural consequences of government suppression and clubber adaptations. My conclusion is that as the rave inspired clubculture was increasingly driven underground in China, three important social characteristic of the clubculture - sociality, community and socioeconomic equality - were seriously undermined.

To some extent, my approach traded depth for breadth. This was a conscious methodological choice because my research goal was to map the development of contemporary Chinese clubculture rather than to elaborate particular micro processes of nightlife consumption. Data for this study was primarily collected through participant observation in dance clubs and ethnographic interviews with clubbers, local officials, and club operators in China between mid-1999 and mid-2002. A major part of the participant observation was carried out in Shanghai, Wuhan, and Beijing, and a minor part of it in Guangzhou, Shenzhen and Chengdu. These cities represented the six party cities with most the prosperous dance club scenes in China at the time. I spent on average three nights per week observing parties in dance clubs, karaoke establishments and other settings in the three years, for around eight hours per night. There was a hierarchy of clubs in every big party city in China which were stratified along the dimensions of socioeconomic class and degree of globalization. I visited club venues that belonged to all different strata because club practices could be very different in them. I visited over thirty venues (including clubs and other nightlife establishments) multiple times in each of my three main cities (Shanghai, Wuhan and Beijing). I did not visit many gay clubs, however, because this study does not focus on issues of gender and sexuality.

I was an outsider to the club scene of China when I began this research in 1999, though I had ample clubbing experiences in Hong Kong and the United States. I approached the clubland in each of the six cities through identifying suitable participants in my social networks of Hong Kongers who worked in China. Then through snowballing, I shifted my fieldwork attention to local participants with a focus on veteran clubbers, frequent and dedicated clubbers, wealthy clubbers and socially underprivileged clubbers. The snowballing process went very smoothly because of my identity. I let my research subjects know that I was an overseas Chinese scholar doing research on clubculture. Very different types of local clubbers - including successful businessmen, Chinese celebrities, criminal gang members, middle-agers, expatriates, hostesses and poor college students - agreed to be involved in the research. The participant observation was conducted at club nights organized by these different types of local clubbers. I travelled where they chose to go and joined them in most of their activities. I joined in late-night meals, part of the routine of Chinese nights-out, where I conducted ethnographic interviews. In most cases, even though I was relatively unknown, participants were very willing to speak up amid the relaxed after-party atmosphere. 


\section{Background: Dominance of the Rave Inspired Clubculture in China, 1996-2002}

According to veteran club operators in Shanghai and Beijing, a few dance clubs were established as early as the late 1980s in Shanghai, Beijing and Guangzhou. At that time, a tiny number of Chinese and expatriate populations in these globalizing cities participated in clubbing. When the contemporary clubculture associated with raves, Ecstasy and electronic dance music emerged at the end of the 1980s in the UK, it was not immediately known or received in China. In the early 1990s, dance clubs were founded in a growing number of Chinese cities. But the party culture supported by these clubs resembled the localized disco clubculture of 1980s Hong Kong and Taiwan more than rave parties (Farrer 1999). The phrase "dance club" was seldom used and clubs were referred to as "discos". The music was mainly pop, Ecstasy was rarely taken in these discos, and social attributes of clubbers were very heterogeneous. Contemporary clubculture influenced only an elite minority of clubbers in China in the early 1990 s - a minority composed of international students, expatriates, young members of the new rich and members of the underworld.

Towards the mid-1990s, a steadily growing number of Chinese clubbers came to embrace rave inspired clubculture. Even though rave parties were rarely organized in China, clubbers developed a taste for Ecstasy, came to appreciate electronic dance music, and began to feel at home with a localized version of rave inspired clubculture. This clubculture reached a critical mass by 1997 and then developed into a mainstream nightlife form in China in 1998 and 1999. I observed that dozens of new clubs were established in each of the first tier party cities in China (ie. Shenzhen, Shanghai, Guangzhou and Beijing) and in a number of second tier ones (eg. Wuhan, Chengdu and Fuzhou). Playing techno and Cantopop electronic dance music, serving only bottled water (due to the dehydration effect of Ecstasy), and operating until the late morning, these clubs reflected a clear break from Chinese disco clubs of the early 1990s. This clubculture continued to spread outside the highly globalized provinces and coastal metropolises into hinterland cities and mid-size towns in the 2000s (Chew 2009a). Both the elite, globalized club circuit and the mass-oriented, localized club circuit witnessed such changes.

The rise of the rave inspired clubculture was so fast and abrupt that the Chinese state did not immediately realize its social significance and did not know how to react. In 1998 and 1999, no coordinated efforts were made to regulate dance clubs or clubbers' open usage of drugs. Although the Chinese state has always adopted a suppressive policy towards drug use, it did not seriously treat Ecstasy as a menace at that time. Instead, local officials were more eager to milk the new clubculture for personal gains - such as protecting dance club businesses for a fee - than to suppress it, especially when there were no central government directives for suppressive action. The unfettered growth of this clubculture lasted until the end of 1999, when the central government finally began to pay serious attention to the new clubculture and devised ways to squash it. Many dance clubs were closed down at this time. In the several cities where I have performed fieldwork, I observed that about half of the existing dance clubs went out of business. The clamp down continued at least until early 2002 in most cities, though the intensive phase had ended earlier in some.

Despite suppression by the government and its subsequent contraction, the rave inspired clubculture still dominated Chinese clubland in 2001 and 2002 because no clubculture was available to replace it. The post-rave and hip-hop clubcultures did not 
arrive in China until the mid-2000s. In the early 2000s, the rave inspired clubculture evolved through adaptations and compromises instead of unbridled expansion. More recently, the central state abandoned the policy of high-handed, indiscriminate suppression of clubbing. Between 2003 and the present, the local governments of numerous cities have been allowed to proactively develop night-time economies and nightlife districts (Chew 2007). Prime urban locations, adequate infrastructure and a legal framework that is more sympathetic to socially deviant nightlife activities were provided (Chew forthcoming 2010). Tamer forms of nightlife culture were subtly encouraged while the rave inspired clubculture was discouraged. The latest generation of localized clubcultures - those that accord with state imperatives - emerged in the mid2000s. In the present, domesticated versions of rave clubculture co-exist with hip-hop clubculture and hybridized local nightlife cultures that mix together bar, karaoke and live music performances (Chew forthcoming 2009b).

\section{Government Suppression of the Rave Inspired Clubculture}

\section{Unregulated drug use before 2000}

The drug Ecstasy is an integral part of rave culture. Apart from energizing the crowd for all-night-long clubbing activities, Ecstasy works symbiotically with electronic dance music to generate music-somatic bodily reactions, facilitates an Oceanic and religious feeling, and encourages the collective values of PLUR (peace, love unity and respect) (Malbon 1999; Reynolds 1998). Drugs tend to play an even more important role in Chinese clubland than Western ones.

In the late 1990s, Ecstasy use was not strictly regulated in China. Chinese clubbers were able to take drugs in dance clubs openly without risks and club operators were not worried about clubbers openly taking drugs in their venues. For example, in the local club circuit in 1998, it was common to observe clubbers who sat by the main dance floor popping Ecstasy and leaving a small pack of pills on their table. In VIP rooms, it was common to find Ecstasy pills, cocaine, marijuana and other drugs neatly arranged on the table. Clubbers took Ecstasy openly and continuously shake their heads. Female clubbers transformed the "head-shake" motion into a dance pattern, swirling their heads rhythmically to the music as they danced. Head shaking and the head swirl dance are localized bodily reactions of Chinese clubbers to Ecstasy highs. Groups of topless men would hug and dance in unison at near-overdose delirium. Ironically, my expatriate and overseas Chinese subjects were not used to these activities because drug use is generally less unfettered in North America.

Local officials (or their relatives) collect under-the-table protection fees from or own shares in the absolute majority of nightlife business in China including commercial sex businesses and dance clubs. This is an open secret to which club operators and veteran clubbers can testify. That was why individual police raids targeting illegal drug use in dance clubs in 1998 were ineffective. The raided clubs usually revert to a business-as-usual status a few days (or weeks) later, with the help of local officials. The suppression campaign in 2000 was different, however. Many criminological and official reports on the use of Ecstasy in Chinese clubculture were published around 2000 (eg. Cheng 2002; Liu 2001). The anti-drug campaign of 2000 was widely rumored to have been initiated personally by the General Secretary Jiang Zemin. Under this context of determined central state initiatives, local officials could no longer maintain their profitable rent-seeking relationship with local dance clubs 


\section{Anti-drug suppression: the case of Shanghai}

How heavily the anti-drug campaign impacted on clubland may be illustrated with the case of Shanghai. Shanghai's clubland tended to be one of the least suppressed in China due to the city's focus on economic development and its expatriate club crowds. But even Shanghai's clubland could not escape the brunt of the campaign. Between 1997 and 1999, clubbers could openly use drugs in a number of clubs. Club JBL, Club Huaer Jie (Club Wall Street), Zhenai Disco (True Love Disco), and Jinye Xingguang Disco (Tonight's Starlight Disco) were the largest and most high profile among them. In early 2000, both JBL and Huaer Jie were closed down permanently. Zhenai had to tame its club crowds and drug use there became much less conspicuous. Jinye Xingguang was able to postpone its demise until 2001 because it was strategically located in an ungoverned geographic location at the intersection of three police precincts. Numerous smaller clubs were also closed down.

Shanghai's clubbers migrated to small, low-profile and newly opened clubs after the first round of clamp downs in 2000. But the Shanghai police immediately identified these clubs, raided them and permanently shut down most of them. Club Fangchengshi (Club Formula), for example, was a nicely decorated club that opened in 2000. It was located on the third floor and had no front entrance or signs. Only clubbers who were in-the-know could find and get admission into the club. Despite its extremely low profile, it was raided frequently and soon disappeared. Older small clubs such as Huangcheng Disco (Imperial City Disco), Club Jingweixian (Club Grid) and Club Hongfen Jiaren (Club Pink Lady) had to operate very sporadically and were eventually forced to close down. The global club circuit frequented only by tourists, expatriates and the upper class in Shanghai was relatively immune to the anti-drug raids in 2000. The police targeted the clubs that attracted Ecstasy users and most of these belonged to the local club circuit. There were a few clubs in the global club circuit that also attracted Ecstasy users. Since their owners were expatriates and/or overseas Chinese, the police had to go through more paperwork to get to them, but they too fell eventually. Among these were Club Babylon, which went down in 2001, Butterfly Bar which closed its doors in 2001, and Buddha Bar which was shut down in 2002.

\section{The nation-wide nature of the suppression}

The state's suppression of clubland was a nation-wide effort. The dance clubs in hinterland urban centers such as Wuhan and Chengdu were as heavily suppressed as those developed coastal cities such as Shanghai, Shenzhen and Guangzhou. In Wuhan, for example, all dance clubs were ordered to stop doing business in August 2001 and many of them had to remain closed for months (Anonymous 2001). According to my observation, at least half of the over 100 dance clubs in Wuhan went out of business that year. Even the administratively separate city of Hong Kong began to tightly control drug use in 2000. Between 1997 and 1999, the rave scene had grown rapidly in Hong Kong. By early 2000, a few rave parties took place every weekend. Then Hong Kong police started to raid drug-centered clubs more frequently, though it did not fully adopt the hardliner suppression tactics of police in China. The police hassled ravers by conducting body searches of those entering a party and making ravers wait in unnecessarily long queues. These soft punitive tactics were effective, as they quickly cut down the number of rave parties to a few per month after 2001. Favorite local rave spots, 
such as the Regal Hotel at Tsimshatsui and Regal Riverside Hotel in Shatin, had to permanently discontinue their operations.

The anti-drug campaign not only shut down the operation of dance clubs and rave parties, it directly impacted clubbers. Local police and officials easily make use of the anti-drug campaign to extract fees from clubbers, as China is an authoritarian country with completely dysfunctional legal and legislative systems. There is no way to hold officials accountable for their (mis)conduct. For example, the police can indiscriminately detain all clubbers in a dance club they are raiding without conducting any drug tests. In localities where the police tend to indiscriminately treat all clubbers as illegal drug users, clubbing becomes a high risk activity even for those who never use drugs. While in Shanghai, police treatment of clubbers was relatively transparent and lawful, in smaller and inland cities, anti-drug campaigns became another opportunity for local officials to generate extra income.

\section{Police rent-seeking in anti-drug campaigns: the case of Wuban}

It is common in China for local officials to re-interpret and carry out central government directives in ways which primarily serve their purpose of seeking rent. In the case of the anti-drug campaign in Wuhan (the major city of Central China), for example, I found that local police use the anti-drug campaign as an excuse to extract fines from clubbers.

Despite Wuhan's mediocre pace of economic development and globalization (relative to China's coastal metropolises), it developed into one of the most important party cities in China from the mid-1990s. Based on industry insiders' observations and the foreign alcohol wholesale figures, Wuhan's clubland rivaled that of Beijing and Shanghai in term of size. The Wuhan city police had their work cut out when the antidrug campaign commenced in 2000. They raided dozens of the drug-centered clubs and continually arrested clubbers who frequented the remaining dance clubs. The police would release clubbers only if they paid informal fines. According to my interlocutors, the fine ranged from 2,000 to 10,000 yuan (at that time, 10 yuan approximated \$1.00 USD) for most clubbers, but there is a case of a Hong Kong clubber paying 12,000 yuan to be released. The police adjusted the sum according to their estimation of how much the arrested clubber could maximally afford, with the estimation based on observations like the model of mobile phone the clubber carried or what $\mathrm{s} / \mathrm{he}$ wore. Although the fine was considered unreasonable by most clubbers, they would still pay it because they feared being taken to drug rehabilitation centers in which serious rights abuses can occur.

As more and more clubbers were intimidated by the anti-drug campaign and police rent-seeking, the police arrested clubbers more arbitrarily and indiscriminately. For example, there were repeatedly raids on the nationally famous club Qiaokou Tiantian (Daily Disco at Qiaokou), one of earliest national bases of local electronic dance music. Many clubbers were detained without being tested for drug use, including some of my research participants who had never taken drugs and others who had not taken drugs on that particular night. In 2001, the police in Wuhan changed their tactics and stopped raiding Qiaokou Tiantian. Instead, they set up an ambush outside the front entrance to the club after three o'clock to arrest clubbers leaving the premises. By refraining from raiding the club, the police kept drug-centered clubs such as Qiaokou Tiantian from going out of business, while at the same time ensuring a steady stream of fine-paying clubbers. To avoid the almost nightly ambush, my interlocutors and I al- 
ways left through a side exit that took us to a neighboring public park. From there, we could walk to taxis parked 300 meters from the front entrance.

\section{Adaptations to Government Suppression}

\section{Club operators' adaptations}

Dance club operators were forced to accommodate to the suppressive environment in 2000. They tried to disassociate themselves from drug use and to monitor clubber behavior inside club premises. At the entrance of many clubs, they posted announcements that prohibited drug use, described relevant laws and listed potential penalties. Inside the clubs, a large number of security guards were stationed at critical spots (the middle of the dance floor, corners and second level spaces) to discipline clubber behavior. The security guards would intervene when observing illegal drug use, head-shake dancing, men removing their tops and other actions suggestive of Ecstasy use. Bottled water was the predominant drink at drug-centered dance clubs before the suppression campaigns, but since water consumption signifies Ecstasy use, many clubs stopped supplying bottled water after 2000 .

Another club adaptation involved the partitioning of open spaces into enclosed rooms. Partitioned spaces are a popular interior design feature in China, where, for example, many restaurants devote a large proportion of their floor space to enclosed rooms. Partitioned spaces became more prevalent in dance clubs from 2000. Firstly, the spatial arrangement offered security and discretion for drug consumption for clubbers who could afford it. With lockable doors and toilets, the occupants of these rooms were afforded adequate time to discard illegal substances in cases of police raids. Secondly, club management could better eschew moral responsibility and legal liability when clubbers were arrested for drug use.

In response to intensified monitoring by police and other officials, many dance clubs were forced to shorten their operating hours, closing at 2:00 or 3:00 AM (instead of 8:00 AM, as was the case in the late 1990s). In periods of strictest control, many had to shut their doors at midnight. In some cases, however, "closing time" became a cover. Thus, even if the lights outside the club entrance were switched off and patrons were not permitted entrance after a certain hour, some clubbers might still be dancing inside until dawn. Clubbers with personal network ties to the management were also allowed to sneak in at any hour. The DJ might have gone, the main dance floor cleared and clubbers may have left the main dance hall, but those who could afford it entered VIP rooms and continued to party to recorded mixes. For example, while a nameless club in Beijing's Chaoyang Park always had its lights dimmed and entrance closed in 2001, it was effectively an operating venue catering specifically to veteran clubbers and Ecstasy users.

While these numerous adaptations were somewhat effective, they were only able to save a fraction of the clubs from going out of business. Clamping down on illegal drug consumption meant that clubs lost the ability to earn commission from drug dealers operating in the premises. The undermining of this significant revenue source led many clubs to close down permanently. There were also other club operators and owners who opted to find other alternatives rather than adapt. One of them, a Taiwanese subject living in Shanghai, explained his reasoning. His main motivation for investing in the business was personal participation in the rave clubculture. When clubculture was harshly suppressed, he lost interest in running his club. He would 
rather host secret private parties in villas in the outskirts of Shanghai than maintaining a club that is constantly under state surveillance and the threat of raids, eventually reinvesting his capital in restaurant businesses.

\section{Clubbers' adaptations}

When state suppression of clubculture was sporadic in 1999, clubbers could avoid police raids by simply switching to clubs protected by corrupt officials or traveling to neighboring or satellite towns with club scenes protected by local officials. But in 2000 , clubbers could no longer do that because few clubs or towns remained impervious to the nationally coordinated campaign.

While dance clubs adapted to state suppression through institutional changes and management arrangements, clubbers adapted through constructing a range of modified and new party practices. Clubbers had to discipline their own behaviors inside dance clubs. For example, they had to avoid doing head-swirling and the head-shake dance. As the police knew these bodily reactions signal Ecstasy consumption, they could easily spot anyone using Ecstasy immediately after they marched into a dance club. The management of the absolute majority of dance clubs started to prohibit their customers from performing head-swirls on the dance floor after 2000. Chinese clubbers had to use lollipops, hugging cushions (as there are plenty of them in VIP rooms), and other bodily reactions to express their Ecstasy highs.

Another favorite clubbing practice that had to be modified was the chanting of clubber composed raps - named high-raps (bidie) by Chinese clubbers - over electronic dance music. Each major party city in China produced dozens of high-raps in their own local dialects in the late 1990s, which clubbers would chant aloud in unison on the dance floor. I have collected more than a hundred of these, most of which contain sexually explicit contents and some of them playful political commentaries, often directed at the Chinese Communist Party and leading political figures. Unsurprisingly, the authoritarian state could not tolerate the dissident content of these raps, with the result that that high-rapping became as heavily suppressed as Ecstasy. Club operators throughout China required their security personnel to prohibit clubbers from high-rapping. While the micro-management efforts required to implement such censorship may have been daunting, the task was taken up with fervor. I witnessed such censorship more than a few times in 2000 as my subjects attempted to high-rap. A small number of new high-raps are still written today and some club DJs occasionally chant them, but it is much less widely diffused than before.

Because many dance clubs shortened their operating hours, clubbers had to find alternative spaces to party after the closing hours. A major solution was what I call "klubbing": a hybridization of clubbing and karaoke entertainment practices (Chew forthcoming 2010). During the anti-drug campaign, there were still underground clubs that stayed open until dawn catering specifically to Ecstasy users. But there were few of them and most did not survive for longer than a few months. Moreover, many were small and inconveniently located away from city centers. The most common after hour alternative club space for clubbers became karaoke rooms within hostess karaoke clubs or karaoke box clubs. ${ }^{1}$ There were usually a few hostess karaoke clubs and karaoke box establishments in each major party city that were willing to accommodate clubbers until morning. Veteran clubbers would know where to locate these clubs and how to get into them. The karaoke rooms were set up like mini clubs, either by the 
management or by clubbers in a makeshift way. The lights were dimmed and non-stop mixes of electronic dance music were played. Some clubbers would even bring their own music CDs, DJ equipment and/or DJs. Clubbers could choose to watch Cantopop, Mandopop techno music videos, psychedelic graphics and animation videos, kung-fu movies, or videos of the dance floor scene taken at local dance clubs. But as klubbing became widely practiced among clubbers, karaoke boxes and hostess clubs eventually became a target of anti-drug raids as well.

A surprising alternative space in which clubbers partied after hours was the taxi cab. The only public transportation available late at night is the taxi, many of which usually parked outside dance clubs waiting for clients. Realizing that clubbers forced out of a prematurely closing club wanted more partying, enterprising taxi drivers would record electronic dance music tapes (because few taxis had CD players in the late 1990s) and play it loudly in the cab. Clubbers who were forced to leave dance clubs would flock to these taxis, even if they were lining up at the end of the taxi queue. Most of the drivers played techno, Cantopop and Mandopop electronic dance music but I have also heard chill-out compilations such as the Café Del Mar series. After boarding the party taxi, clubber often requested drivers to tour around the city center and scenic spots such as bridges for an hour or two. A one-hour ride would cost around 250 yuan in Shanghai and less in other cities. This price was tolerable in comparison to the expenses of an average dance club, especially when three or four clubbers went together.

Many clubbers were middle class white collar workers or businessmen in the daytime. They could not tolerate the risk of going to jail. Some of them became so worried about the suppression campaign that they stopped partying in public and began to organize private parties. The more affluent among them would throw parties in suburban villas, while the moderately well-off did the same in hotel rooms and urban apartments. But the majority of "private parties" held by non-affluent clubbers were actually non-spectacular events held in private residences. For example, one of my research subjects turned her tiny and old apartment into a club almost every night within a period of two months in 2001. She would invite two or three close friends, some of whom invited other friends. She equipped the apartment with ultraviolet neon lights, gadgets that glow in the dark, candles and shiny wall decorations. While clubbing in a private space was, on the whole, safer than dance clubs, it still held risks. If neighbors complained to the police, the police would likely arrive at the scene before the party ended and they would arrest the participants. Anticipating neighbor complaints, the hosts of private parties in hotel rooms and private homes often took great care to avoid disturbing neighbors.

\section{Socio-cultural Implications of Adapting to Government Suppression}

Government suppression has generated negative socio-cultural consequences for clubcultures in China. As dance clubs and clubbers adapted to the suppression, clubland managed to survive and provided the context for new local clubcultures to emerge in the mid-2000s. But there are important consequences to the adaptive tactics. Most obviously, drug use became more restricted, certain clubbing practices had to be abandoned and certain music practices have been self-censored. But in addition to these, there were hidden socio-cultural costs that were no less significant. 


\section{The undermining of sociality}

Sociality is one such cost. One of the cultural shocks that my non-Chinese clubbing subjects typically experience in the current local club circuit in China is the altered and diminished role that sociality plays in dance clubs. Sociality is one of the major rationales for clubbing. Dance clubs function as a platform for individuals to socialize with others who share similar interests in music, drugs, and fashion; to meet and date total strangers; and to develop bonding with acquaintances and friends (Communication Studies 298 1997; Grazian 2008). Commonly, the dance floor, bar tables and common open areas of dance clubs provide the spatial stage where clubbers socialize with one another. But the interior spatial arrangement of Chinese dance clubs do not facilitate sociality so strongly. Many of the adaptive tactics adopted by clubbers and club management illustrate this tendency. For example, many Chinese dance clubs have over half of their floor space sectioned into numerous enclosed rooms. Each of these rooms is occupied by a particular group of clubbers who are willing to pay the minimum charge. Many Chinese clubbers are willing to pay this premium since, as previously discussed, it insures them against the risk of being arrested.

These rooms become semi-private mini clubs within dance venues, the entrance to which is regulated by different groups of clubbers. Socialization among strangers is restricted because clubbers who pay for the rooms are not likely to invite strangers inside indiscriminately. Although open areas still remain in most Chinese dance clubs, their potential to facilitate sociality is undermined by the existence of the private rooms. If about half of the clubbers in a dance club hide inside enclosed spaces and do not even publicly show their face to others, the "to-see-and-be-seen" element of clubbing sociality is inevitably hampered. The staging of clubbing activities through klubbing practices in the karaoke boxes of karaoke establishments and hostess clubs undermines sociality even more strongly since these venues do not feature any open areas at all. The same argument also applies to private parties in hotel rooms and private homes.

\section{The undermining of community}

Another indirect cost of the adaptive tactics was the undermining of the community dimension of clubculture (Goulding, Shankar and Elliott 2002). With a large party space and significant numbers of participants, the rave setting can be described in terms of Durkheimian "collective effervescense" or Freudian "oceanic" feeling (Malbon 1999). Whereas rave parties were a signature clubbing format in the West in the 1990s, they were the least available among all clubbing formats in China. Participants of the global clubbing circuit in China often complained that they seldom had the opportunity to experience rave parties even while they had much experience with its associated music and drugs. The main reasons for the unavailability of rave parties were political and commercial risks. The political risk was the state's aversion to gatherings of large crowds not initiated or controlled by officials, and the commercial risk was caused by the susceptibility of rave parties to rent-seeking by officials from numerous bureaus.

While the political and commercial risks for any large-scale party production were already substantial before 2000, these increased after the suppression campaign began. The smaller a club was, the more likely that it could deflect risks. But a smallscale club setting was also less likely to facilitate a communal and spiritual atmosphere. The enclosing of dance club space into semi-private rooms is exemplary. In rave par- 
ties, hundreds or thousands of ravers listen to the same music mixed live by the DJ, experience the same lighting and ambience, and dance in proximity to one another. But Chinese dance clubs, VIP rooms within dance clubs, karaoke boxes within a hostess or karaoke establishment, private apartments or hotel rooms cannot be the contexts for such a collective atmosphere. These constrained spaces undermine psychological immersion and prevent strangers from participating in each other's energy.

Some clubbing practices were as important as club spatial setting in facilitating a sense of community in the Chinese context. High-rapping and the singing of local Chinese dance tracks, for example, were powerful practices that moved Chinese clubbers to act collectively in dance clubs. Clubbers would shout out the high-raps in unison, often with the initiation and prompting of DJs or MCs. But after the state signaled disapproval of high-rapping in a high profile way through the official media, club managers became wary and censored the high-rapping of clubbers, DJs and MCs in their clubs. Although high-rapping can still be carried out in the VIP rooms of dance clubs, karaoke boxes and private homes, these constrained spaces generate less collective energy and communal outcomes.

\section{The exacerbation of socioeconomic stratification}

The third hidden cost of the adaptive tactics is the exacerbation of socioeconomic stratification in Chinese nightlife. In the early 1990s, Chinese dance clubs typically accommodated clubbers from extremely diverse socioeconomic backgrounds (Farrer 2002). But as the nightlife market expanded in the late 1990s, different dance clubs gradually developed their niches through catering to different socioeconomic groups. An inter-club hierarchy was established in each of the several major party cities in China by the late 1990s. The global dance club circuit attracted white expatriate males, overseas Chinese males, upper-middle class local Chinese males and young local Chinese females. The clubs of this circuit are usually located in the central business districts, prime retail districts, scenic tourist spots or diplomatic districts. The local club circuit, which primarily attracts middle and lower income local Chinese, was once scattered throughout the city and is now aggregated in government-planned nightlife districts.

Apart from the industrial development towards stratification from the early 1990 s to the late 1990s, the adaptive tactics of club management and clubbers led to an additional dimension of stratification in clubland in the early 2000s. Adaptive tactics resisting state suppression often required the mobilization of resources. Some of these resources were free. For example, at a private party in her apartment, one subject took blankets from her bed to block off her doors and windows in order to prevent noise leakage. While this noise-prevention measure was entirely costless and broadly adopted by the private party hosts I have met, other tactics would incur costs. The provision of relatively safe spaces for clubbing often required substantial expenses ranging from audio equipment to suburban villas - expenses largely transferred to clubbers or the hosts. In other words, only clubbers and hosts who had the economic means and/or social connections to cover such expenses could enjoy safe and risk-free clubbing. Clubbers without the requisite social and economic capital either had to either bear the full risks of state suppression or quit clubbing.

Another development towards social hierarchy involves the polarization of global and local club circuits. Some dance clubs attempted to alleviate police pressure by repositioning themselves as prestigious, expensive and cosmopolitan clubs for the upper 
middle class. Other dance clubs moved deeper underground by relocating to very marginal areas in the city, restricting entrance and operating irregularly. Lower income clubbers were intimated by the posh cosmopolitan clubs, whereas upper-middle class clubbers were turned off by the organized criminal affiliation of underground clubs. The polarization of global and local club circuits intensified during the early $2000 \mathrm{~s}$ as a result. It only abated more recently after club operators invented new market positioning tactics - such as the re-packaging of dance clubs as middle-class lounge bars to distract police attention.

\section{Conclusion}

The previous analysis demonstrates that the rave inspired clubculture that prospered in late 1990s China stagnated in the early 2000s because of harsh suppression by the state. It is found that club operators and clubbers somewhat successfully adapted to the suppression campaign by modifying club spaces, practices and culture. But the adaptations generated negative socio-cultural consequences for Chinese clubculture: the undermining of sociality inside dance clubs, the weakening of the communal dimension of clubculture and the exacerbation of socioeconomic stratification in clubland.

A few years after high-handedly suppressing clubland, the Chinese state took an unprecedented turn in dealing with nightlife: it began to embrace the night-time economy as a means of culture-led urban renewal, a cultural industry infrastructure, a tourist attraction and a source of local tax revenue. The suppression of the rave inspired clubculture was not entirely relaxed. But the state has indeed replaced heavyhanded suppression campaigns by administratively encouraging domesticated, socially and politically non-threatening clubcultures. Clubbers and club operators are of course taking advantage of the state's partial relaxation of suppression to re-engage in relatively unfettered forms of party practices. For example, after the popularity of Ecstasy declined Chinese clubbers followed the global fashion of drug consumption and discovered ketamine and other varieties of recreational drugs. A new dynamic of state regulation of clubland, clubber resistance and clubcultural transformation is transpiring at present, a dynamic that is more subtle and complex than that documented in this study. The investigation of this new dynamic will be a valuable future research direction.

\section{Acknowledgements}

I would like to thank Graham St John and the two anonymous reviewers for their valuable comments on my paper.

\section{References}

Anonymous. 2001. "Yu Dupin Baoli Seqing Guagou Wuhan Suoyou Diba Tingye Zhengdun” (Due to connections to drugs, violence, sex, all dance clubs in Wuhan have to reform and quit operating), online news article posted on August 24, 2001.

<http://past.people.com.cn/BIG5/shehui/45/20010824/542908.html> (accessed 20 June 2002).

Chatterton, Paul and Robert Hollands. 2003. Urban Nightscapes: Youth Culture, Pleasure Spaces and Corporate Power. London: Routledge. 
Cheng, Hengbing. 2002. “'Yaotouwan' Anjian Tedian ji Zhencha Duice” (The characteristics and investigative approaches to Ecstasy cases). Journal of Guangxi Public Security Management Cadres Institute 55: 39-41.

Chew, Matthew M. 2007. "Nightlife Districts in Urban China". The International Conference on China's Urban Land and Housing in the 21st Century. Hong Kong Baptist University.

----. Forthcoming 2009a. "Cultural Localization and its Local Discontents: Contested Evaluations of Cantopop Electronic Dance Music". Social Transformations in Chinese Societies 5.

----. 2009b. "A New Party Politics: the State and the Night-Time Economy in China in the 2000s". The Conference on China Studies: Past Present and Future. Hong Kong Baptist University.

----. Forthcoming 2010. "Hybridization of Karaoke and Dance Clubbing Practices in Chinese Nightlife". In Contemporary Asian Modernities, edited by Eva Man Kit-wa and Stephen Chu Yiu-wai, Peter Lang.

Communication Studies 298. 1997. "Fragments of Self at the Postmodern Bar". Journal of Contemporary Ethnography 26(5): 251-92.

Farrer, James. 2002. Opening Up: Youth Sex Culture and Market Reform in Shanghai. Chicago: Chicago University Press.

----. 1999. "Disco 'Super-Culture': Consuming Foreign Sex in the Chinese Disco". Sexualities 2(2): 147-65.

Goulding, Christina, Avi Shankar, and Richard Elliott. 2002. "Working Weeks, Rave Weekends: Identity Fragmentation and the Emergence of New Communities". Consumption, Markets and Culture 5(4): 261-84.

Grazian, David. 2008. On the Make: The Hustle of Urban Nightlife. University of Chicago Press. Liu, Endi. 2001. "Lun Xifang Dupin Wenhua Dui Woguo de Shentou yu Wuran" (On the diffusion and contamination of Western drug culture in China). Journal of Liaoning Adminstrators College of Police 22: 55-7.

Malbon, Ben. 1999. Clubbing: Dancing, Ecstasy and Vitality. London: Routledge.

McCall, Tara. 2001. This Is Not a Rave: In the Shadow of a Subculture. Toronto: Insomniac Press.

McKay, George. 1998. DiY Culture: Notes towards an Intro. In George McKay (ed), DiY Culture: Party \& Protest in Nineties Britain, pp. 1-53. London: Verso.

Owen, Frank. 2003. Clubland: The Fabulous Rise and Murderous Fall of Club Culture. New York: St. Martins Press.

Reynolds, Simon. 1998. Generation Ecstasy: Into the World of Techno and Rave Culture. Boston: Little, Brown and Company.

Saldanha, Arun. 2002. "Music Tourism and Factions of Bodies in Goa". Tourist Studies 1: 43-62.

Sliavaite, Kristina. 1998. "When Global Becomes Local: Rave Culture in Lithuania”. M.A. Thesis, (Social Anthropology), Lund University.

Swedenburg, Ted. 2001. "Trance-National Islam, World Music, and the Diaspora". The Annual Meeting of the Middle East Studies Association. (San Francisco).

Thornton, Sarah. 1996. Club Cultures: Music, Media, and Subcultural Capital. Hanover; London: University Press of New England.

\section{Author Biography}

Matthew M. Chew is an Assistant Professor in the Department of Sociology, Hong Kong Baptist University. His research interests include cultural sociology, globalization, social movements, new media, nightlife, fashion, intellectual history, cultural policy and social theory. His work deals with a variety of empirical materials including early modern Japanese universities, Chinese dance clubs and online games.

\section{Notes}

1 The major difference between hostess karaoke clubs and karaoke box establishments is the presence of hostesses (ie. women who provide romance and sex work) in hostess karaoke clubs. 